\title{
The Voronovskaja theorem for some linear positive operators defined by infinite sum
}

\section{DAN MicLĂUŞ and OvidiU T. POP}

\section{ABSTRACT.}

The main goal of this paper is to establish a Voronovskaja type theorem for the Szász-Mirakjan-Schurer operators. As a particular case, we get also the Voronovskaja type theorem for the well known Mirakjan-Favard-Szász operators.

DePARTMENT OF MATHEMATICS AND COMPUTER SCIENCE

NORTH UNIVERSITY OF BAIA MARE

Victoriei 76, 430122 BAIA MARE, ROMANIA

E-mail address: danmiclausrz@yahoo.com

National College "Mihai Eminescu"

Mihai EminesCu 5, 440014 SATU MARe, Romania

E-mail address: ovidiutiberiu@yahoo.com 